meeting MCP joints $2-5$ of 6 patients with RA were assessed twice on the same day by all experts using US machines (GE) equipped with high-frequency transducers $(18-22 \mathrm{MHz})$ with presets calibrated for the appropriate assessment of cartilage. Participants assessed metacarpal cartilage both in the standardized longitudinal midline scan as well as by freehand technique utilizing multiple planes and scored by the semiquantitative scoring system. Intraobserver reliability was assessed by Cohen's kappa and interobserver reliability by Fleiss' kappa.

Results: The three-grade semiquantitative (Grade 0, normal cartilage; Grade 1, minimal change; Grade 2, severe change) scoring system demonstrated excellent (kappa: 0.87 ) to good (kappa: 0.73 ) intraobserver reliability in the webbased exercise and the patient-based reliability study respectively. Interobserver reliability was good in the web-based exercise (kappa: 0.64 ) and moderate (kappa: 0.49 ) in the patient-based reliability study. The dynamic technique performed slightly better than the longitudinal midline scan alone.

Conclusions: A semiquantitative scoring system demonstrated good intra- and moderate to good inter-observer reliability in a web-based exercise and patientbased reliability study. Our study demonstrates that US is a reliable tool for evaluating cartilage and supports the use of a new semiquantitative US scoring system for evaluating cartilage change in RA.

Acknowledgements: The patient-based reliability study was supported by a research grant from UCB.

Disclosure of Interest: None declared

DOI: 10.1136/annrheumdis-2017-eular.4314

\section{OP0289 TREAT-TO-TARGET IN EARLY RHEUMATOID ARTHRITIS: ASSOCIATION BETWEEN SUSTAINED REMISSION AND JOINT DAMAGE}

N.P. Sundlisater ${ }^{1}$, A.-B. Aga ${ }^{1}$, I.C. Olsen ${ }^{1}$, H.B. Hammer ${ }^{1}$, T. Uhlig ${ }^{1}$, D. van der Heijde $^{2}$, T.K. Kvien ${ }^{1}$, S. Lillegraven ${ }^{1}$, E.A. Haavardsholm ${ }^{1}$ on behalf of The Arctic study group. ${ }^{1}$ Diakonhjemmet Hospital, Oslo, Oslo, Norway; ${ }^{2}$ Leiden University Medical Center, Leiden, Netherlands

Background: Modern treatment of early RA is targeted towards remission. Sustained remission is viewed as more beneficial to the patient than remission at one time point, also with regards to inhibition of joint damage, $(1,2)$ but data are limited. Treat-to-target studies yielding high rates of sustained remission have improved the ability to assess the relationship between sustained remission and joint damage.

Objectives: To assess the frequency of no radiographic progression among early RA patients in sustained remission defined by established criteria and in patients with sustained absence of inflammation assessed by ultrasound.

Methods: RA patients with $<2$ years from first swollen joint who were DMARD naive with indication for DMARD treatment were included in the ARCTIC trial.(3) Patients in the ultrasound arm aiming for DAS $<1.6$, no swollen joints and no ultrasound power Doppler (PD) signal were included in the current analyses. Several definitions of sustained remission (12-24 months) were compared; DASESR, DAS28-ESR, SDAI, CDAI, ACR/EULAR Boolean remission (based on 44 joints), no swollen joints (44SJC), no ultrasound PD signal in any joint (0-96) and minimal total ultrasound greyscale (GS) score (defined as GS $\leq 2,0-96$ ). No radiographic progression (12-24 months) was defined as $<1$ unit change in the van der Heijde modified Sharp score (vdHSS). Positive and negative likelihood ratios of no radiographic progression were estimated for patients in sustained remission per definition.

Results: Of 103 patients, 76 (74\%) were female, mean [SD] age was 51.4 [12.9] years, disease duration 6.7 [5.3] months and DAS 3.5 [1.1]. The median [25th, 75th percentile] change in vdHSS $12-24$ months was $0.49[0.0,1.03]$, and $73(71 \%)$ patients had no radiographic progression. Sustained remission was reached by $23-61 \%$ according to the different criteria. Among patients in sustained remission, comparable proportions of patients did not progress radiographically across the

Table The performance of sustained remission 12-24 months for identifying patients without radiographic progression in the same time period. Significant likelihood ratios in bold.

\begin{tabular}{|c|c|c|c|c|}
\hline & \multirow{2}{*}{$\begin{array}{c}\text { Patients in } \\
\text { sustained } \\
\text { remission } \\
12-24 \text { months, } \\
\text { n(\%) } \\
\end{array}$} & \multirow{2}{*}{$\begin{array}{c}\text { Patients in } \\
\text { sustained } \\
\text { remission and no } \\
\text { radiographic } \\
\text { progression } 12- \\
24 \text { months, } n(\%) \\
\end{array}$} & \multicolumn{2}{|c|}{$\begin{array}{l}\text { Likelihood ratios of no } \\
\text { radiographic progression } \\
12-24 \text { months }\end{array}$} \\
\hline & & & $\begin{array}{c}\mathrm{LR}+ \\
(95 \% \mathrm{CI}) \\
\end{array}$ & $\begin{array}{c}\text { LR- } \\
(95 \% \mathrm{CI})\end{array}$ \\
\hline \multicolumn{5}{|l|}{ Clinical outcomes } \\
\hline $\mathrm{DAS}<1.6$ & $46(45)$ & $37(80)$ & $\begin{array}{c}1.69 \\
(0.94,3.05)\end{array}$ & $\begin{array}{c}0.70 \\
(0.51,0.98)\end{array}$ \\
\hline DAS $28<2.6$ & $54(52)$ & $40(74)$ & $\begin{array}{c}1.17 \\
(0.76,1.82)\end{array}$ & $\begin{array}{c}0.85 \\
(0.56,1.29)\end{array}$ \\
\hline $\mathrm{SDAI} \leq 3.3$ & $33(32)$ & $26(79)$ & $\begin{array}{c}1.53 \\
(0.74,3.13)\end{array}$ & $\begin{array}{c}0.84 \\
(0.65,1.09)\end{array}$ \\
\hline $\mathrm{CDAI} \leq 2.8$ & $31(30)$ & $26(84)$ & $\begin{array}{c}2.14 \\
(0.91,5.04)\end{array}$ & $\begin{array}{c}0.77 \\
(0.61,0.98)\end{array}$ \\
\hline $\begin{array}{l}\text { ACR/EULAR Boolean } \\
\text { (based on } 44 \text { joints) }\end{array}$ & $24(23)$ & $18(75)$ & $\begin{array}{c}1.23 \\
(0.54,2.80)\end{array}$ & $\begin{array}{c}0.94 \\
(0.75,1.18)\end{array}$ \\
\hline $\begin{array}{l}\text { SJC44=0, } \\
\text { (range } 0-44 \text { ) }\end{array}$ & $50(49)$ & $39(78)$ & $\begin{array}{c}1.46 \\
(0.87,2.44)\end{array}$ & $\begin{array}{c}0.74 \\
(0.51,1.06)\end{array}$ \\
\hline \multicolumn{5}{|l|}{ Ultrasound } \\
\hline $\begin{array}{l}\mathrm{PD}=0, \\
\text { (range 0-96) }\end{array}$ & $63(61)$ & $51(81)$ & $\begin{array}{c}1.75 \\
(1.10,2.78)\end{array}$ & $\begin{array}{c}0.50 \\
(0.32,0.79)\end{array}$ \\
\hline $\begin{array}{l}\text { GS } \leq 2 \\
\text { (range 0-96) }\end{array}$ & $27(26)$ & $24(89)$ & $\begin{array}{c}3.29 \\
(1.07,10.10)\end{array}$ & $\begin{array}{c}0.75 \\
(0.61,0.91) \\
\end{array}$ \\
\hline
\end{tabular}

different criteria (74-89\%), with the most favorable result for minimal GS score (Table). Patients with sustained no PD or minimal GS score had an increased likelihood of no radiographic progression during the concurrent year (Table), but still rather weak to be useful in an individual patient. Based on the low LR+ none of the criteria identifies patients without radiographic progression very well; likewise, as the LR- is relatively high for all definitions, not being in remission does not change the probability of ongoing radiographic progression substantially.

Conclusions: In this treat-to-target early RA study, sustained remission rates were generally high and radiographic progression limited. None of the sustained remission criteria were able to exclude concurrent radiographic progression. Absence of ultrasound inflammation performed best of the definitions assessed. References:

[1] Aletaha D, et al. A\&R. 2009;60(5).

[2] Lillegraven S, et al. ARD. 2012;71(5)

[3] Haavardsholm EA, et al. BMJ. 2016;354.

Disclosure of Interest: N. Sundlisater: None declared, A.-B. Aga: None declared, I. Olsen: None declared, H. Hammer Consultant for: AbbVie, Pfizer, BMS, Roche, UCB, T. Uhlig: None declared, D. van der Heijde: None declared, T. Kvien: None declared, S. Lillegraven: None declared, E. Haavardsholm Grant/research support from: AbbVie, Pfizer, MSD, Roche, UCB

DOI: 10.1136/annrheumdis-2017-eular.2366

\section{OP0290 CORRELATION OF CXCL13 AND ULTRASSONOGRAPHIC FINDINGS OF JACCOUD ARTHROPATHY IN SYSTEMIC LUPUS ERYTHEMATOSUS}

D.S. Ribeiro ${ }^{1}$, C. Lins ${ }^{1}$, E. Pimenta ${ }^{1}$, V. Galvão ${ }^{1}$, W. Santos ${ }^{1}$, V. Machicado ${ }^{1}$, C. Baleeiro ${ }^{1}$, A. Pedreira ${ }^{1}$, A.P. Duque ${ }^{1}$, G. Rosa ${ }^{1}$, A. Atta ${ }^{2}$, I. Oliveira ${ }^{2}$, M. Santiago ${ }^{1}$. ${ }^{1}$ Escola Bahiana de Medicina e Saúde Pública; ${ }^{2}$ Faculdade de Farmácia, Universidade Federal da Bahia, Salvador, Brazil

Background: Joint involvement in systemic lupus erythematosus (SLE) is one of the earliest manifestation of the disease (1).Only $2-5 \%$ of the cases develop a deforming and non-erosive type of arthritis, known as Jaccoud Arthropathy (JA). Until now, there is no serum autoantibodies marker for it (2). The chemokine CXC ligand 13 protein $(\mathrm{CXCL} 13)$ is one of the most potent B-cell chemo attractants and is constitutively expressed in the B-cell follicles of secondary lymphoid organs (3). Its seric level has been associated to the degree of synovitis in patients with rheumatoid arthritis as studied by ultrasonography (US).

Objectives: To perform the first detailed US analysis of hands and wrists of SLE patients, with and without $\mathrm{JA}$, and to correlate those findings with the levels of CXCL13,other clinical and laboratory features and disease activity

Methods: 64 patients with SLE were included, being 32 with JA and 32 without JA paired by age and disease duration. The definition of JA was based on clinical criteria recently described by Santiago (4). Patients and controls underwent a highresolution US exam of wrists and hands. Synovial hypertrophy,tenosynovitis and erosions were evaluated according a semi-quantitative grading system according definitions provided by OMERACT (5). Serum concentrations of CXCL13 were quantified in both groups utilizing a commercially available kit. Autoantibodies such as antinuclear antibody (ANA), anti-dsDNA, anti-Sm, anti-SSA, anti-SSB were also tested. US findings were correlated with seric levels of CXCL13, other serological parameters and SLEDAI score.

Results: In the JA group, the mean age was 46.2 years and the mean duration of the disease was 17.3 years. Synovitis on US was found in 25 patients and tenosynovitis in 14. All of these findings were more frequent in SLE with JA, particularly tenosynovitis with difference statistically significant $(p=0.002)$. In JA patients the median levels of CXCL13 was $23.21 \mathrm{pg} / \mathrm{ml}$ as compared to 11.48 $\mathrm{pg} / \mathrm{ml}$ in SLE without JA group $(\mathrm{p}=0.08)$. There was an association between tenosynovitis and higher levels of CXCL13 in the JA group $(p=0.026)$. Patients with active disease were more common in the JA group $(p=0.004)$ and had increased serum levels of CXCL13 compared to patients with disease inactive $(p=0.008)$.

Conclusions: In conclusion, the present study is one of a few to describe US findings in SLE patients with JA and it confirms that synovitis and tenosynovitis are common features in the majority of these patients. In addition, CXCL13 may be regarded as a biomarker for tendon inflammation in JA.

\section{References:}

[1] Messuti LZ, A. Joint Involvement in SLE: Controversy of RHUPUS. INTERNATIONAL TRENDS IN IMMUNITY. 2014;2(4):155-61.

[2] Galvao V, Atta AM, et al. Profile of autoantibodies in Jaccoud's arthropathy. Joint Bone Spine. 2009 Jul;76(4):356-60.

[3] Zheng B, Ozen Z, et al. CXCL13 neutralization reduces the severity of collagen-induced arthritis. Arthritis Rheum. 2005 Feb;52(2):620-6.

[4] Santiago MB. Jaccoud's arthropathy: proper classification criteria and treatment are still needed. Rheumatology intern. 2013 Nov;33(11):2953-4.

[5] Wakefield RJ. The OMERACT Ultrasound Group: status of current activities and research directions. The Journal of rheumatology. 2007 Apr;34(4):848-51.

Disclosure of Interest: None declared

DOI: 10.1136/annrheumdis-2017-eular.2998 